\title{
Identification by HPLC-MS of Anthocyanin Derivatives in Raisins
}

\author{
Ana Marquez, ${ }^{1}$ Montserrat Dueñas, ${ }^{2}$ María P. Serratosa, ${ }^{1}$ and Julieta Merida ${ }^{1}$ \\ ${ }^{1}$ Department of Agricultural Chemistry, Faculty of Sciences, University of Cordoba, Edificio Marie Curie, \\ Campus de Rabanales, 14014 Cordoba, Spain \\ ${ }^{2}$ Polyphenols Research Group, Nutrition and Bromatology Section, Faculty of Pharmacy, \\ Campus Miguel de Unamuno, 37007 Salamanca, Spain \\ Correspondence should be addressed to Julieta Merida; jmerida@uco.es
}

Received 13 June 2012; Accepted 12 August 2012

Academic Editor: Ioannis Kourkoutas

Copyright (C) 2013 Ana Marquez et al. This is an open access article distributed under the Creative Commons Attribution License, which permits unrestricted use, distribution, and reproduction in any medium, provided the original work is properly cited.

The anthocyanin composition in red grapes dried under controlled conditions has been studied. Pyranoanthocyanins and condensed anthocyanins with flavanols by a methylmethine bridge have been identified. Typically, these compounds appear in wine after the fermentation process, as they require compounds such as pyruvic acid, acetoacetic acid, and acetaldehyde for their formation. During the chamber-drying process a stress situation is originated, inducing significant changes in the grape metabolism from aerobic to anaerobic, and as a result it produces the activation of the alcohol dehydrogenase enzyme (ADH) and others that would cause the formation of these compounds. These derivatives are very interesting because they give greater stability to the color of red wine.

\section{Introduction}

The pyranoanthocyanins are compounds formed in wine during aging. They are responsible for the red-purple color of red wines and evolve progressively toward brown colors, since these adducts have a more reddish-orange color than their anthocyanins counterparts.

The pyranoanthocyanins are formed from condensation reactions on anthocyanins, which are modified to result in stable oligomers from substitutions at position C4. Their general structure (Figure 1) includes an additional Dring formed between the $\mathrm{OH}$ group at $\mathrm{C} 5$ and the $\mathrm{C} 4$ of the anthocyanin pyran ring [1]. This new pyran Dring formed, which is responsible for the name of these compounds, may have different substituents directly linked to C10. This structural characteristic is the source of the greatest intensity of color and stability of pyranoanthocyanins in a broader $\mathrm{pH}$ range than the original anthocyanins $[2,3]$. These compounds have an absorption peak between 495 and $520 \mathrm{~nm}$, that is, a hypsochromic effect is observed compared to the starting anthocyanins [4-6]. In addition, they have an absorption peak in the $420 \mathrm{~nm}$ region, explaining the orange hues of these compounds [7].
The vitisins are one of the most studied pyranoanthocyanin families and are originated by the reaction of anthocyanins with some metabolites released during the fermentation of yeast, such as pyruvic acid, acetoacetic acid, and acetaldehyde $[2,7,8]$, the latter could be in wine as a result of the ethanol oxidation.

Since a long time ago, the condensation of the anthocyans with flavanols by a methylmethine bridge or not has been studied by different authors [9-11]. Specifically, in the anthocyanin-methyilmethine-flavanol adducts the absorption peak presents a bathochromic shift compared to the corresponding monomer, finding the $\lambda_{\max }$ between 530 and $540 \mathrm{~nm}$, which gives the molecules blue-red or purple hues. This color shift has been observed both in model solutions $[12,13]$ and in experimental red wines [14].

The inclusion of anthocyanin $\mathrm{C} 4$ into the pyran ring causes the steric hindrance which makes the pyranoanthocyan molecule more stable to bleaching by the $\mathrm{SO}_{2}[2,5,15]$, increase of $\mathrm{pH}[5,11,16]$, to oxidative degradation [17], and even to temperature [18]. Therefore, the aim of this work has been to identify, by HPLC-MS, the presence of condensation adducts of anthocyanins with flavanols via methylmethine bridges and pyranoanthocyanins in red grapes dried under controlled humidity and temperature. 
<smiles>[R3]C1=CC2=C(OC)C(c3cc([R])c(O)c([R2])c3)=[O+]c3cc(O)cc(c31)O2</smiles>

FIGURE 1: General structure of pyranoanthocyanins.<smiles>COc1cc2c(O)cc(O)cc2[o+]c1-c1ccc(O)cc1</smiles>

FIGURE 2: Structure of pelargonidin-3-glucoside.

\section{Experimental}

2.1. Reagents. All the anthocyanins standards were purchased from Extrasynthèse (Genay, France) and a calibration curve was obtained by injection of different concentration. Methanol, formic acid, ethyl acetate, acetonitrile and purified water were purchase from Merck (Madrid, Spain).

2.2. Grape Drying. The material used in this study consisted of Syrah grapes from the Montilla-Moriles region (southern Spain). This was uniformly distributed in several trays and allowed to dry in a Frisol Climatronic chamber at an air temperature of $40^{\circ} \mathrm{C}$ and a constant relative humidity of ca. $20 \%$ [19].

2.3. Analytical Techniques. The measurement of reducing sugars was performed by refractometry, using a refractometer model Atago Master (Master Baume 2594, Atago, Japan).

Pyruvic acid was determined enzymatically, using a KPYRUV 03/07 kit from Megazyme (Wicklow, Ireland).

The ethanol content was determined according to Crowell and Ough [20], to this end, ethanol in the sample was

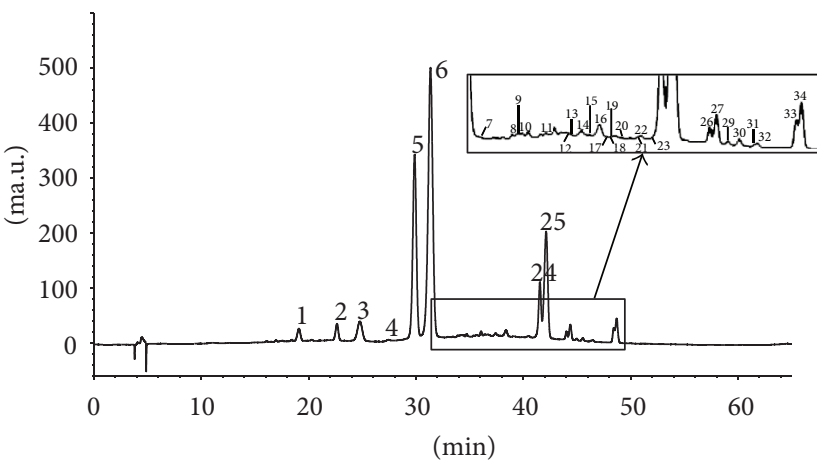

FIGURE 3: HPLC-DAD chromatogram at $520 \mathrm{~nm}$ of anthocyanins of the must from raisins.

collected by steam and then reacted with acid potassium dichromate. The reaction was spectrophotometrically monitored via the absorbance at $600 \mathrm{~nm}$ against a blank on a Perking Elmer Lambda 25 spectrophotometer.

The extraction of anthocyanins was performed by using Sep-Pak C18 cartridge (Long Body Sep-Pak Plus; Waters Associates, Milford, MA). A volume of $2 \mathrm{~mL}$ of must was passed through the cartridge, with $900 \mathrm{mg}$ of filling that was previously activated with $5 \mathrm{~mL}$ of methanol and washed with aqueous $\mathrm{HCl} 0.01 \%(\mathrm{v} / \mathrm{v})$. The cartridge was washed successively with $10 \mathrm{~mL}$ of $0.01 \%$ aqueous $\mathrm{HCl}$ and $5 \mathrm{~mL}$ of ethyl acetate and anthocyanins were recovered with $5 \mathrm{~mL}$ of acidified methanol at $\mathrm{pH}$ 2. The extracts were analysed using a Hewlett-Packard 1100 series liquid chromatograph (Agilent Technologies, Waldbronn, Germany) [19]. Detection was carried out in a diode array detector (DAD), using $520 \mathrm{~nm}$ as the preferred wavelength, and in a mass spectrometer (MS) connected to the HPLC system via the DAD cell outlet. MS detection was performed in a API 3200 Qtrap (Applied Biosystems, Darmstadt, Germany) equipped with an ESI source and a triple quadrupole-ion trap mass analyzer that was controled by the Analyst 5.1 software [21].

For acetaldehyde quantification, an Agilent 6890 series plus gas chromatograph (Agilent Technologies, Waldbronn. Germany) with electronic pressure control was used [22]. The column, a CPWAX-57 CB model from Chrompack (Middelburg, The Netherlands), was fused silica $60 \mathrm{~m} \times 0.25 \mathrm{~mm}$ and $0.40-\mu \mathrm{m}$ film thickness. The chemstation software package (Agilent Technologies, Waldbronn. Germany) was used. 1 $\mathrm{ml}$ of a solution containing $1 \mathrm{~g} / \mathrm{L}$ of 4 -methyl- 2 pentanol as internal standard was added to $10 \mathrm{~mL}$ of sample, and an aliquot of $0.5 \mu \mathrm{L}$ was injected.

\section{Results and Discussion}

Table 1 shows the identified compounds in the musts from red grapes by HPLC-DAD-MS. As can be seen, firstly, monoglucosides derivatives were identified, five of which are present in most red varieties: delphinidin-3-glucoside (peak 1), cyanidin-3-glucoside (peak 2), petunidin-3glucoside (peak 3), peonidin-3-glucoside (peak 5), and 


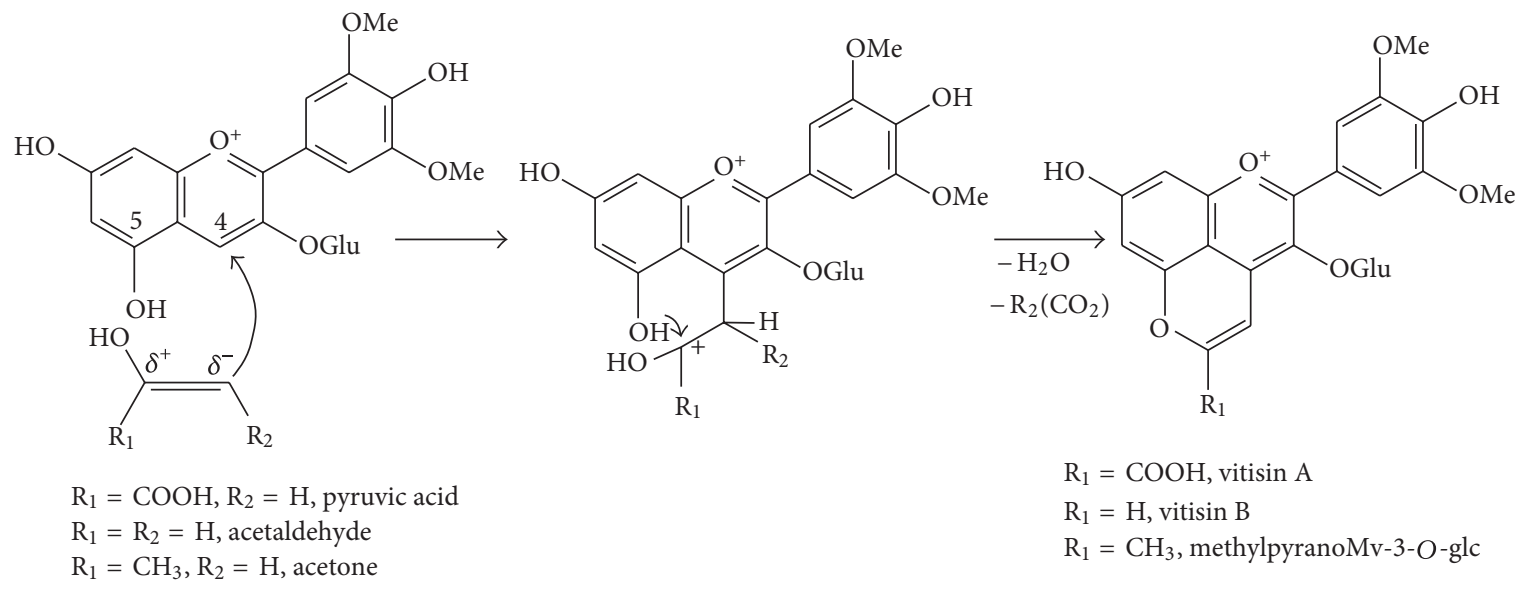

FIGURE 4: Formation of pyranoanthocyanin compounds by reaction between malvidin-3-glucoside and carbonyl compounds (enolic forms).

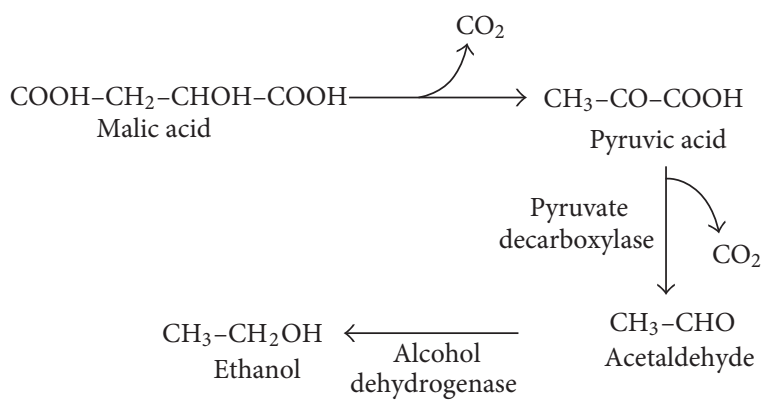

FIGURE 5: Enzymatic reactions of carbonic maceration.

malvidin-3-glucoside (peak 6), peak 4 was identified as pelargonidin-3-glucoside, whose structure is shown in Figure 2. The MS analysis of pelargonidin-3-glucoside produced a $\left[\mathrm{M}^{+}\right]$peak at $m / z 433$ and a fragment at $m / z 271$. This anthocyanin was identified in grapes of nonvinifera varieties Concord, Rubired, and Salvador [23, 24] and recently in Vitis vinifera grapes of Garnacha Tintorera [25]. These authors suggested that the presence of this compound could be used as a chemical marker to identify red wines of this variety, however, after finding this compound in new grape varieties the hypothesis could be revised.

Other monomeric anthocyanins identified were the acetic esters of delphinidin (peak 8), cyanidin (peak 14), petunidin (peak 16), peonidin (peak 24), and malvidin (peak 25). Also, the caffeoylglucosides of petunidin, peonidin, and malvidin were identified as peaks 23, 26, and 27 and finally the peaks 29-34 were assigned to the $p$-coumarylglucosides derivatives of cyanidin, petunidin, peonidin, and malvidin. In relation to these latter compounds, it was possible to differentiate the cis-and trans-isomers of coumarylglucosides of peonidin (peaks 31 and 33), both with a $\left[\mathrm{M}^{+}\right]$ion at $\mathrm{m} / z 301$ and malvidin (peaks 32 and 34), with $\left[\mathrm{M}^{+}\right]$at $m / z 331$.
All of these anthocyanin derivatives have been identified in the musts from fresh grapes. However, in musts from raisins new compounds were also identified, which were synthesized during the drying process of the grapes, pyranoanthocyanins, and condensation compounds anthocyaninmethylmethine-flavanol, whose chromatograms are shown in Figure 3.

Some authors insure that the way of formation of the pyranoanthocyanins, called vitisins (Figure 4), begins with the addition of small metabolites of the positions 4 (carbon) and 5 (hydroxyl group) of anthocyanins, followed by a dehydration and an oxidation, obtaining the D-ring [1]. Specifically, the formation of type A vitisins, also called carboxipyranoanthocyans, under acidic conditions such as exist in red wines are caused by the interaction between the enol form of pyruvic acid with an anthocyanin [7]. The chromatographic characteristic of peak 7 showed a $\left[\mathrm{M}^{+}\right]$ion at $m / z 561$ and a fragmentation with $m / z 399$ and the peak 10 a $\left[\mathrm{M}^{+}\right]$ion at $m / z 603$ and a fragmentation with $\mathrm{m} / z 399$. These peaks agreed with those of vitisin A and acetylvitisin A, respectively, first identified by Bakker and Timberlake [2] and whose starting anthocyanins are malvidin-3-glucoside and malvidin-3-acetilglucoside. To confirm the formation of these derivatives, the pyruvic acid content in musts was determined, finding concentrations of $20.5 \pm 0.437 \mathrm{mg} / \mathrm{L}$ in raisins and below the detection limit in musts from fresh grapes. Considering that the analyzed musts were not fermented, the presence of pyruvic acid would be due to another way of formation during the drying process of the grapes.

So, the fruit dehydration involves a stress situation inducing significant changes in their metabolism [26]. In the particular case of grapes, Bellicontro et al. [27] showed that the stress situation took place when the weight loss was 10-15\% if they were dried in tunnels at $21^{\circ} \mathrm{C}$. Furthermore, according to Chkaiban et al. [28] the loss of water in the grape berries during the drying process leads to changes in the membrane permeability through the activation of lipooxygenase enzyme 


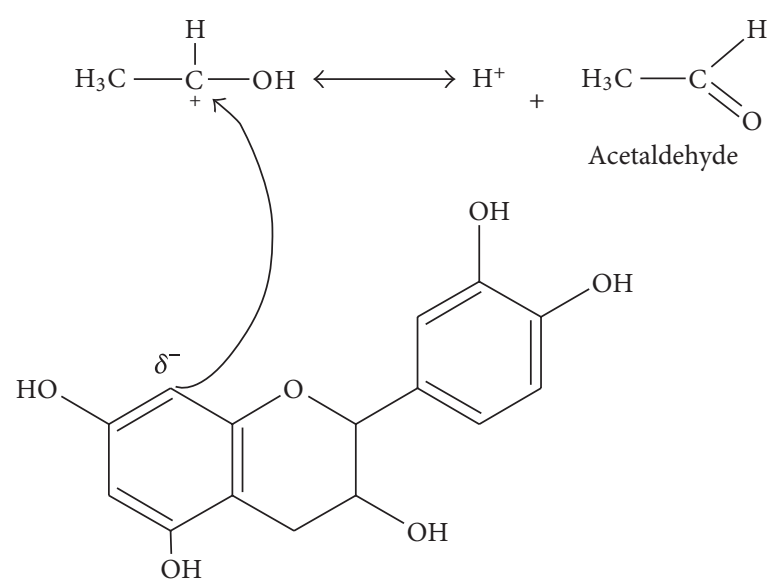<smiles>CC(C)CC(=O)c1c(O)cc(O)c2c1OC(c1ccc(O)c(O)c1)C(O)C2</smiles><smiles>COc1cc2c(O)cc(O)cc2[o+]c1-c1cc(OC)c(O)c(OC)c1</smiles><smiles></smiles>

FIGURE 6: Formation of anthocyanin-methylmethine-flavanol compounds by reaction between (+)-catechin and malvidin-3-glucoside.

(LOX). This fact produces a change in the berry's metabolism from aerobic to anaerobic, resulting in the activation of the alcohol dehydrogenase enzyme (ADH). Under these anaerobic conditions during drying other enzymes could be activated, capable of degrading sugars and/or malic acid from grapes to pyruvic acid, which would justify the contents of this acid found in raisin musts.
In addition, in the musts from raisins, type B vitisins were determined, which differ from carboxipyranoanthocyans because the carboxyl group is missing at the $\mathrm{C} 10$ position of the D-ring. These vitisins are formed by the addition of one acetaldehyde molecule on an anthocyanin molecule (Figure 4). Peak 11 showed the chromatographic characteristics of the so-called vitisin B. This piranoanthocyan is 
TABLE 1: Retention times, mass spectral, and UV-Vis data of anthocyanins identified in musts from raisins after chamber drying.

\begin{tabular}{|c|c|c|c|c|c|}
\hline Peak & $R_{t}$ & $\mathrm{M}^{+}(m / z)$ & $\mathrm{MS}^{2}$ frag. & $\lambda_{\max }(\mathrm{nm})$ & Compound \\
\hline 1 & 19.10 & 465 & 303 & 524 & Dp-3-glc \\
\hline 2 & 22.65 & 449 & 287 & 516 & Cy-3-glc \\
\hline 3 & 24.81 & 479 & 317 & 526 & Pt-3-glc \\
\hline 4 & 27.46 & 433 & 271 & 506 & Pg-3-glc \\
\hline 5 & 29.91 & 463 & 301 & 518 & Pn-3-glc \\
\hline 6 & 31.37 & 493 & 331 & 528 & Mv-3-glc \\
\hline 7 & 32.25 & 561 & 399 & 490 & Vitisin A \\
\hline 8 & 33.90 & 507 & 303 & 528 & Dp-3-acetylglc \\
\hline 9 & 34.23 & 487 & 325 & 486 & B-type vitisin Pn-3-glc \\
\hline 10 & 34.43 & 603 & 399 & 490 & A-type vitisin Mv-3-acetylglc \\
\hline 11 & 35.66 & 517 & 355 & 490 & Vitisin B \\
\hline 12 & 36.90 & 779 & - & 530 & Pn-3-glc-methylmethine(epi)catechin \\
\hline 13 & 37.25 & 809 & 357 & 530 & Mv-3-glc-methylmethine(epi)catechin \\
\hline 14 & 37.46 & 491 & 287 & 518 & Cy-3-acetylglc \\
\hline 15 & 37.86 & 809 & 357 & 540 & Mv-3-glc-methylmethine(epi)catechin \\
\hline 16 & 38.42 & 521 & 317 & 528 & Pt-3-acetylglc \\
\hline 17 & 38.60 & 529 & 325 & 494 & B-type vitisin Pn-3-acetylglc \\
\hline 18 & 39.07 & 779 & - & 528 & Pn-3-glc-methylmethine(epi)catechin \\
\hline 19 & 39.07 & 559 & 355 & 494 & B-type vitisin Mv-3-acetylglc \\
\hline 20 & 39.28 & 809 & 357 & 542 & Mv-3-glc-methylmethine(epi)catechin \\
\hline 21 & 40.47 & 809 & 357 & 530 & Mv-3-glc-methylmethine(epi)catechin \\
\hline 22 & 40.50 & 779 & - & 528 & Pn-3-glc-methylmethine(epi)catechin \\
\hline 23 & 41.10 & 641 & 317 & 522 & Pt-3-caffeoylgluc \\
\hline 24 & 41.58 & 505 & 301 & 520 & Pn-3-acetylglc \\
\hline 25 & 42.16 & 535 & 331 & 532 & Mv-3-acetylglc \\
\hline 26 & 44.05 & 625 & 301 & 522 & Pn-3-caffeoylglc \\
\hline 27 & 44.41 & 655 & 331 & 534 & Mv-3-caffeoylglc \\
\hline 28 & 44.46 & 851 & - & - & Mv-3-acetylglc-methylmethine(epi)catechin \\
\hline 29 & 44.99 & 595 & 287 & 520 & Cy-3-coumaroylglc \\
\hline 30 & 45.55 & 625 & 317 & 534 & Pt-3-coumaroylglc \\
\hline 31 & 46.20 & 609 & 301 & 526 & Pn-3-coumaroylglc cis \\
\hline 32 & 46.50 & 639 & 331 & 538 & Mv-3-coumaroylglc cis \\
\hline 33 & 48.44 & 609 & 301 & 524 & Pn-3-coumaroylglc trans \\
\hline 34 & 48.71 & 639 & 331 & 538 & Mv-3-coumaroylglc trans \\
\hline
\end{tabular}

originated when the cycloaddition is carried out on malvidin3-glucoside $[4,15]$. Spectroscopic characteristics of this compound showed a $\left[\mathrm{M}^{+}\right]$at $m / z 517$, fragmentation ion at $m / z 355$ and $\lambda_{\max } 490 \mathrm{~nm}$. Likewise, the peaks 9, 17, and 19 were identified as type B vitisins of peonidin-3-glucoside, peonidin-3-acetilglucoside, and malvidin-3-acetilglucoside, respectively.

The presence of acetaldehyde in the musts from raisins, in the formation of these compounds, would be essential. As a result of the metabolism change discussed above, the pyruvic acid could have been converted into acetaldehyde by decarboxylation. To prove this hypothesis, the musts were analyzed by gas chromatography (GC-FID) for quantification of acetaldehyde. The results showed the absence of this compound in fresh grapes and a content of $128 \pm 7.9 \mathrm{mg} / \mathrm{L}$ in the musts from raisins, indicating that during chamberdrying the acetaldehyde synthesis should take place.
According to the hypothesis about the synthesis of pyruvic acid and acetaldehyde during grape drying, the latter could be reduced to ethanol by the action of the alcohol dehydrogenase enzyme. As a result, ethanol would be the major metabolite produced from sugars and/or malic acid in grapes subjected to anaerobic stress, similar to the reaction that occurs during carbonic maceration (Figure 5). To confirm this hypothesis, the concentration of ethanol in fresh grapes was measured, finding a content of zero, while in raisin musts the concentration was $0.789 \pm 0.003(\mathrm{v} / \mathrm{v})$, indicating that the alcohol dehydrogenase enzyme could convert acetaldehyde into ethanol.

Besides the pyranoanthocyanins, the HPLC-DAD-MS analysis also showed condensation products between anthocyanins and (epi)catechin via a methylmethine bridge, whose compounds need the presence of acetaldehyde. According to the mechanism proposed by Pissarra et al. [29], the 
acetaldehyde in acid medium is subjected to an initial protonation forming the corresponding carbocation, inducing an electrophilic attack on the flavanol phloroglucinol ring, preferably in the $\mathrm{C} 8$ position. The formed adduct reacts with the anthocyanin to yield the new colored compound. The presence of an asymmetric carbon $\left(\mathrm{C}^{*}\right)$ on the created link leads to the formation of two diastereoisomeric structures ( $\mathrm{R}$ and $\mathrm{S}$ ). This mechanism is shown in Figure 6 . In the corresponding chromatograms, the following adducts were identified: three compounds of formula Pn3-glc-methylmethine(epi)catechin (peaks 12, 18, and 22) with $\mathrm{m} / z 779$ and four compounds of formula Mv-3-glcmethylmethine(epi)catechin (peaks 13, 15, 20, and 21) of ratio $m / z 809$ and fragmentation ions at $m / z 357$.

In summary, the presence of pyruvic acid, acetaldehyde, and ethanol would confirm the enzymatic transformations and, therefore, the formation of pyranoanthocyanins and condensation compounds of anthocyanin with flavanols via methylmethine bridge that occurred during the raisining process. These anthocyanin derivatives have a great oenological interest because they confer stability to the color of red wines and have always been identified in wine and not in unfermented musts.

\section{Acknowledgments}

The authors gratefully acknowledge financial support from the Spanish Government, Minister of Education (FPU scholarship of A. Marquez) for the realization of this work. Dr. M. Dueñas also thanks the Spanish "Ramón y Cajal" Program for a contract.

\section{References}

[1] V. de Freitas and N. Mateus, "Formation of pyranoanthocyanins in red wines: a new and diverse class of anthocyanin derivatives," Analytical and Bioanalytical Chemistry, vol. 401, no. 5, pp. 1467-1477, 2011.

[2] J. Bakker and C. F. Timberlake, "Isolation, identification, and characterization of new color-stable anthocyanins occurring in some red wines," Journal of Agricultural and Food Chemistry, vol. 45, no. 1, pp. 35-43, 1997.

[3] J. Oliveira, V. Fernandes, C. Miranda et al., "Color properties of four cyanidin-pyruvic acid adducts," Journal of Agricultural and Food Chemistry, vol. 54, no. 18, pp. 6894-6903, 2006.

[4] C. Alcalde-Eon, M. T. Escribano-Bailón, C. Santos-Buelga, and J. C. Rivas-Gonzalo, "Changes in the detailed pigment composition of red wine during maturity and ageing: a comprehensive study," Analytica Chimica Acta, vol. 563, no. 1-2, pp. 238-254, 2006.

[5] R. E. Asenstorfer, D. F. Lee, and G. P. Jones, "Influence of structure on the ionisation constants of anthocyanin and anthocyanin-like wine pigments," Analytica Chimica Acta, vol. 563, no. 1-2, pp. 10-14, 2006.

[6] A. Morata, F. Calderón, M. C. González, M. C. GómezCordovés, and J. A. Suárez, "Formation of the highly stable pyranoanthocyanins (vitisins A and B) in red wines by the addition of pyruvic acid and acetaldehyde," Food Chemistry, vol. 100, no. 3, pp. 1144-1152, 2007.
[7] H. Fulcrand, C. Benabdeljalil, J. Rigaud, V. Cheynier, and M. Moutounet, "A new class of wine pigments generated by reaction between pyruvic acid and grape anthocyanins," Phytochemistry, vol. 47, no. 7, pp. 1401-1407, 1998.

[8] Y. Hayasaka and R. E. Asenstorfer, "Screening for potential pigments derived from anthocyanins in red wine using nanoelectrospray tandem mass spectrometry," Journal of Agricultural and Food Chemistry, vol. 50, no. 4, pp. 756-761, 2002.

[9] C. F. Timberlake and P. Bridle, "Interactions between anthocyanins, phenolic compounds and acetaldehyde and their significance in red wines," American Journal of Enology and Viticulture, vol. 27, pp. 97-105, 1976.

[10] J. C. Rivas-Gonzalo, S. Bravo-Haro, and C. Santos-Buelga, "Detection of compounds formed through the reaction of malvidin 3-monoglucoside and catechin in the presence of acetaldehyde," Journal of Agricultural and Food Chemistry, vol. 43, no. 6, pp. 1444-1449, 1995.

[11] E. M. Francia-Aricha, M. T. Guerra, J. C. Rivas-Gonzalo, and C. Santos-Buelga, "New anthocyanin pigments formed after condensation with flavanols," Journal of Agricultural and Food Chemistry, vol. 45, no. 6, pp. 2262-2266, 1997.

[12] C. Dallas, J. M. Ricardo-da-Silva, and O. Laureano, "Interactions of oligomeric procyanidins in model wine solutions containing malvidin-3-glucoside and acetaldehyde," Journal of the Science of Food and Agriculture, vol. 70, no. 4, pp. 493-500, 1996.

[13] T. Escribano-Bailón, M. Álvarez-García, J. G. Rivas-Gonzalo, F. J. Heredia, and C. Santos-Buelga, "Color and stability of pigments derived from the acetaldehyde-mediated condensation between malvidin 3-O-glucoside and (+)-catechin," Journal of Agricultural and Food Chemistry, vol. 49, no. 3, pp. 1213-1217, 2001.

[14] A. M. Vivar-Quintana, C. Santos-Buelga, E. Francia-Aricha, and J. C. Rivas-Gonzalo, "Formation of anthocyanin-derived pigments in experimental red wines," Food Science and Technology International, vol. 5, no. 4, pp. 347-352, 1999.

[15] A. M. Vivar-Quintana, C. Santos-Buelga, and J. C. RivasGonzalo, "Anthocyanin-derived pigments and colour of red wines," Analytica Chimica Acta, vol. 458, no. 1, pp. 147-155, 2002.

[16] C. Romero and J. Bakker, "Interactions between grape anthocyanins and pyruvic acid, with effect of $\mathrm{pH}$ and acid concentration on anthocyanin composition and color in model solutions," Journal of Agricultural and Food Chemistry, vol. 47, no. 8, pp. 3130-3139, 1999.

[17] J. Bakker, P. Bridle, T. Honda et al., "Identification of an anthocyanin occurring in some red wines," Phytochemistry, vol. 44, no. 7, pp. 1375-1382, 1997.

[18] P. Sarni-Manchado, H. Fulcrand, J. M. Souquet, V. Cheynier, and M. Moutounet, "Stability and color of unreported wine anthocyanin-derived pigments," Journal of Food Science, vol. 61, no. 5, pp. 938-941, 1996.

[19] A. Marquez, M. P. Serratosa, A. Lopez-Toledano, and J. Merida, "Colour and phenolic compounds in sweet red wines from Merlot and Tempranillo grapes chamber-dried under controlled conditions," Food Chemistry, vol. 130, no. 1, pp. 111-120, 2012.

[20] E. A. Crowell and C. S. Ough, "A modified procedure for alcohol determination by dichromate oxidation," American Journal of Enology and Viticulture, vol. 30, pp. 61-63, 1979.

[21] M. García-Marino, J. M. Hernández-Hierro, J. C. RivasGonzalo, and M. T. Escribano-Bailón, "Colour and pigment 
composition of red wines obtained from co-maceration of Tempranillo and Graciano varieties," Analytica Chimica Acta, vol. 660, no. 1-2, pp. 134-142, 2010.

[22] R. A. Peinado, J. A. Moreno, D. Muñoz, M. Medina, and J. Moreno, "Gas chromatographic quantification of major volatile compounds and polyols in wine by direct injection," Journal of Agricultural and Food Chemistry, vol. 52, no. 21, pp. 6389-6393, 2004.

[23] H. Wang, E. J. Race, and A. J. Shrikhande, "Characterization of anthocyanins in grape juices by ion trap liquid chromatography-mass spectrometry," Journal of Agricultural and Food Chemistry, vol. 51, no. 7, pp. 1839-1844, 2003.

[24] Q. Tian, M. M. Giusti, G. D. Stoner, and S. J. Schwartz, "Screening for anthocyanins using high-performance liquid chromatography coupled to electrospray ionization tandem mass spectrometry with precursor-ion analysis, product-ion analysis, common-neutral-loss analysis, and selected reaction monitoring," Journal of Chromatography A, vol. 1091, no. 1-2, pp. 72-82, 2005.

[25] N. C. Muñoz, M. F. González, S. G. Alonso, E. G. Romero, and I. H. Gutiérrez, "Red-color related phenolic composition of garnacha tintorera (Vitis vinifera L.) grapes and red wines," Journal of Agricultural and Food Chemistry, vol. 57, no. 17, pp. 7883-7891, 2009.

[26] S. J. Kays, "Stress in harvested products," in Postharvest Physiology in Perishable Plants Products, S. J. Kays, Ed., pp. 335-408, Exon Press, Athens, Ga, USA, 1997.

[27] A. Bellincontro, D. De Santis, R. Botondi, I. Villa, and F. Mencarelli, "Different postharvest dehydration rates affect quality characteristics and volatile compounds of Malvasia, Trebbiano and Sangiovese grapes for wine production," Journal of the Science of Food and Agriculture, vol. 84, no. 13, pp. 1791-1800, 2004.

[28] L. Chkaiban, R. Botondi, A. Bellincontro, D. De Santis, P. Kefalas, and F. Mencarelli, "Influence of postharvest water stress on lipoxygenase and alcohol dehydrogenase activities, and on the composition of some volatile compounds of Gewürztraminer grapes dehydrated under controlled and uncontrolled thermohygrometric conditions," Australian Journal of Grape and Wine Research, vol. 13, no. 3, pp. 142-149, 2007.

[29] J. Pissarra, S. Lourenço, A. M. González-Paramás, N. Mateus, C. Santos-Buelga, and V. De Freitas, "Formation of new anthocyanin-alkyl/aryl-flavanol pigments in model solutions," Analytica Chimica Acta, vol. 513, no. 1, pp. 215-221, 2004. 

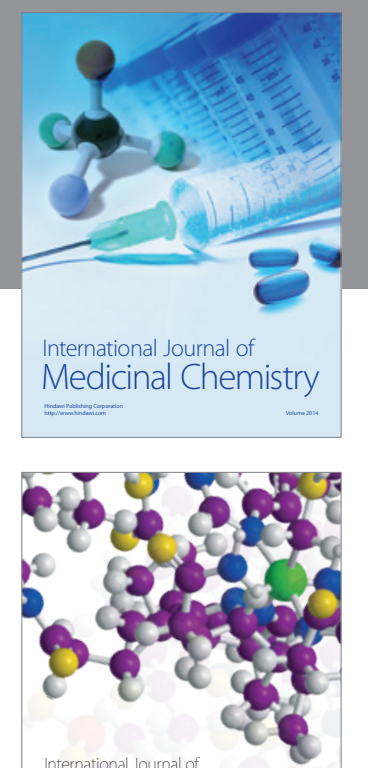

\section{Carbohydrate} Chemistry

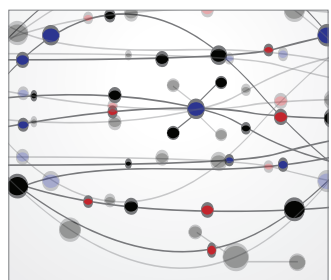

The Scientific World Journal
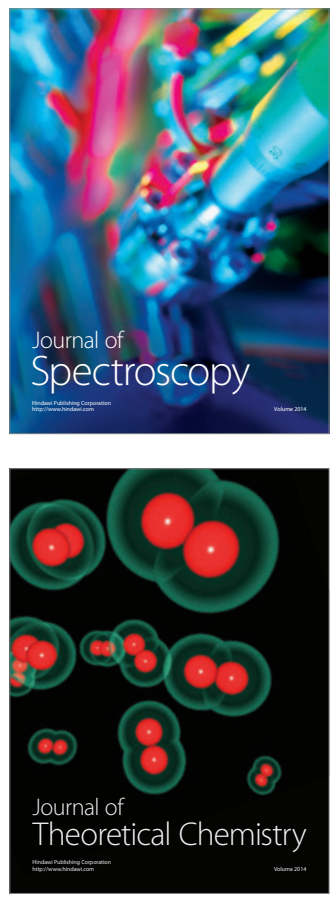
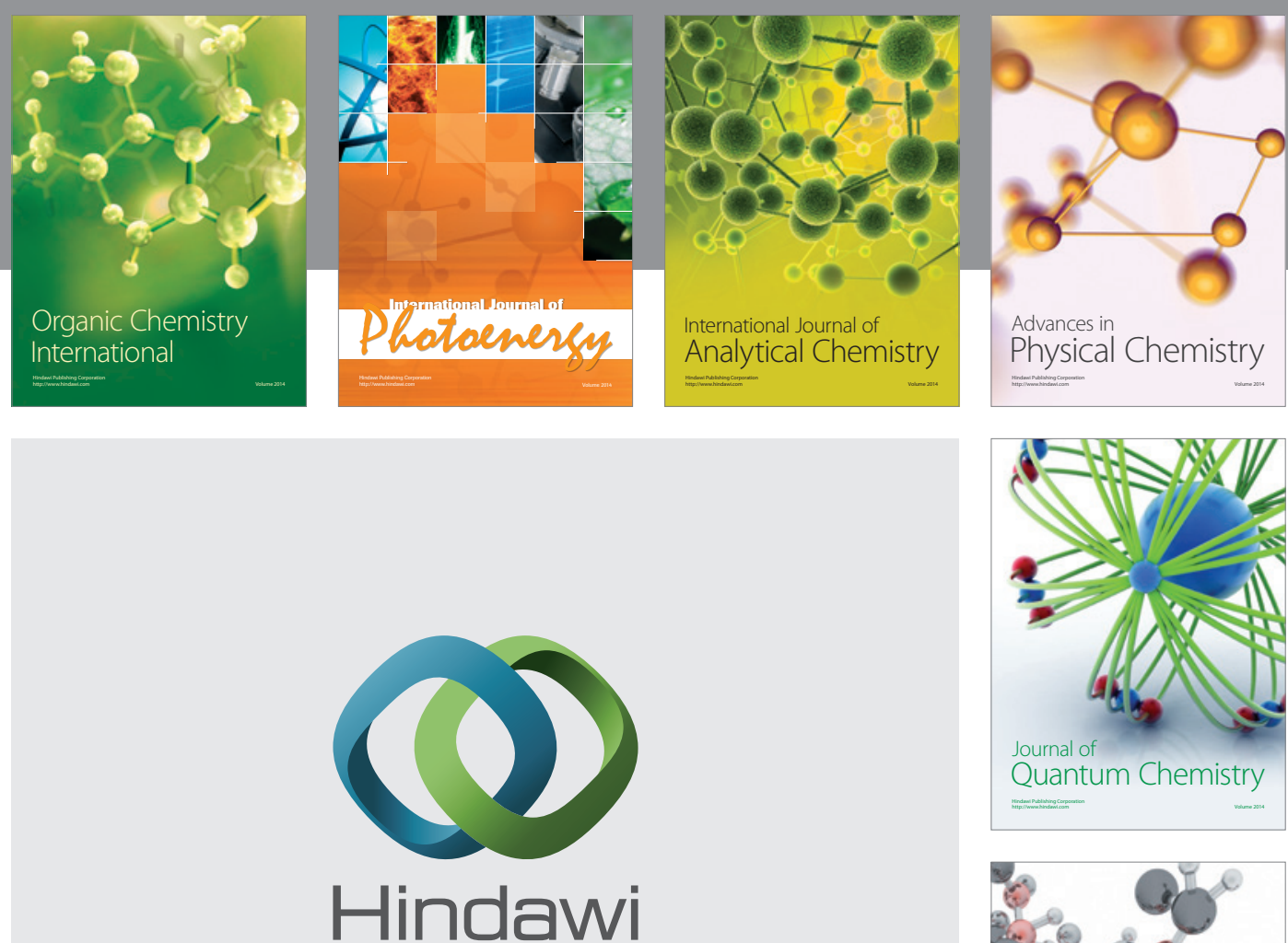

Submit your manuscripts at

http://www.hindawi.com

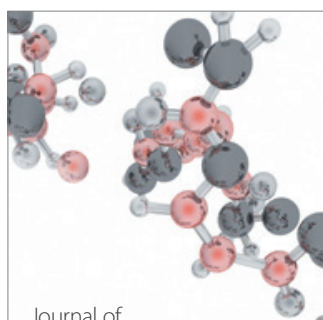

Analytical Methods

in Chemistry

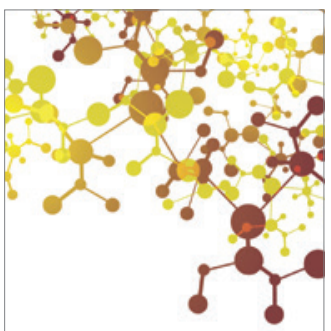

Journal of

Applied Chemistry

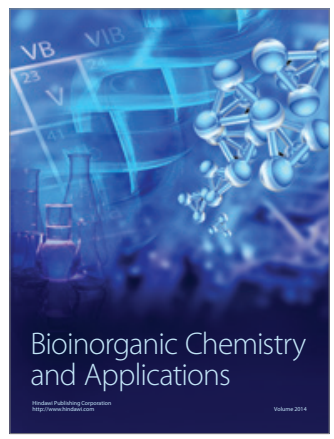

Inorganic Chemistry
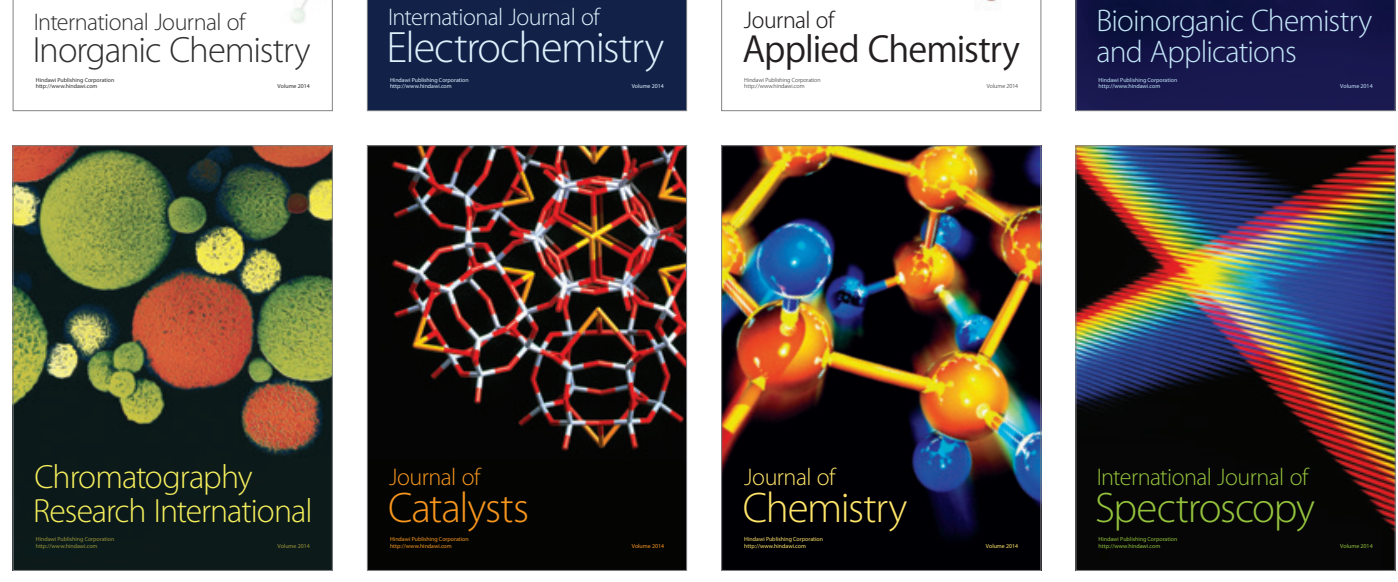